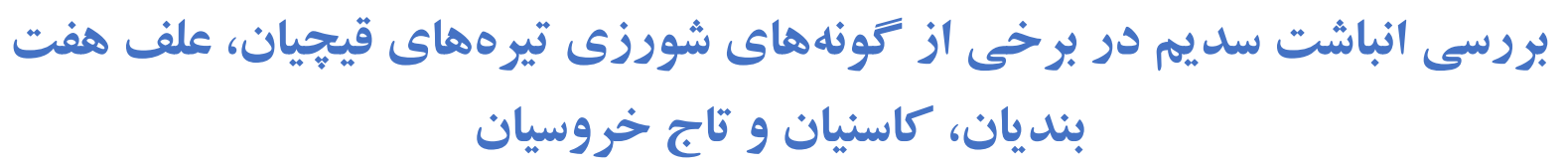

سيد موسى موسوى كوهى، مريم مودى، اسماعيل سلطانى مقدم و هديه سرجاهى مقدم

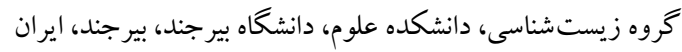

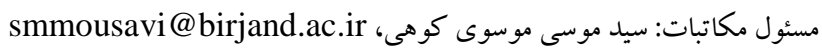

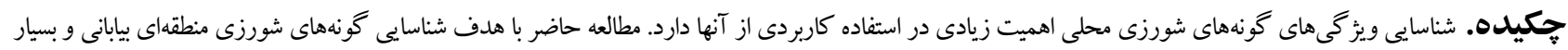

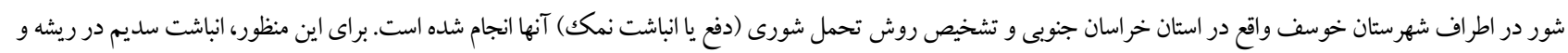

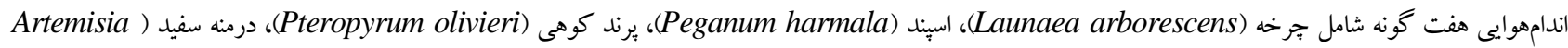

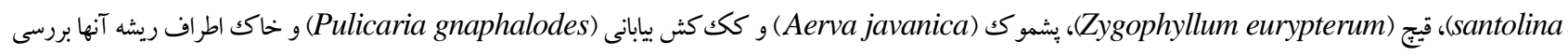
شد. در ادامه، ضريب انباشتخى زيستى سديم (Bioconcentration Factor: BCF) در ريشه، ضريب تراجيى (Translocation factors: TF) آن از ريشه به اندامهوايى و

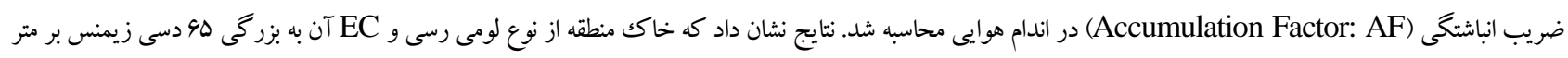
است كه نشان دهنده شورى بسيار زياد خاكك است. بر طبق مقادير نسبت جذب سديم (ds/m)

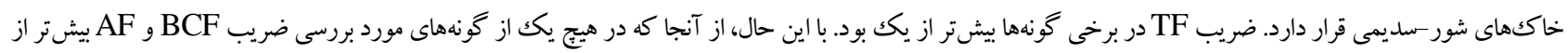

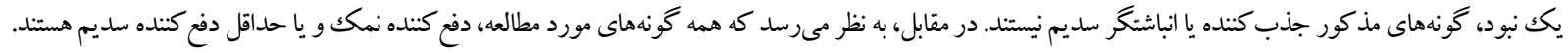

$$
\text { وازههاى كليدى. انباشتخر نمك،، خاكى شور، دفع كننده نمك، ضريب انباشتى زيستى، گياهان شوريسند }
$$

\title{
The investigating of sodium accumulation in some halophytic species of Zygophyllaceae, Polygonaceae, Asteraceae and Amaranthaceae
}

\author{
Seyed Mousa Mousavi Kouhi, Maryam Moudi,Esmael Soltani Moghadam, Hedyieh Sarchahi Moghadam \\ Department of Biology, Faculty of Sciences, University of Birjand, Birjand, Iran \\ Correspondent author: Seyed Mousa Mousavi Kouhi, smmousavi@birjand.ac.ir
}

\begin{abstract}
The identification of the characteristics of native halophytic species is very important for their practical application. The present study was carried out to identify the halophytic species of a desert and highly saline region around the city of Khosf, southern Khorasan Province, and to detect their general tolerance mechanisms (i.e. salt exclusion or inclusion). Sodium accumulation in the roots and shoots of seven species, including Launaea arborescens, Peganum harmala, Pteropyrum olivieri, Artemisia santolina, Zygophyllum eurypterum Boiss, Aerva javanica, Pulicaria gnaphalode, and their rhizosphere soil were determined. The bioconcentration of sodium from soil to roots (BCF), its translocation from roots to shoots (TF), and its accumulation in the shoots (AF) were then calculated. Results showed that the soil of the studied area was clay loam with a high EC of $65 \mathrm{ds} / \mathrm{m}$, indicating its high salinity level. According to the values of sodium adsorption ratio (SAR) and the exchangeable sodium percentage (ESP) and regarding EC, the soil of studied region can be regarded as a saline-sodic soil. The value of TF in some species was higher than 1 . However, none of the species had BCF and AF greater than 1, thus, none of them could be considered to be salt accumulator. Instead, it could be assumed that all of the studied species were salt, or at least, sodium excluders.
\end{abstract}

Keywords. bioconcentration factor, halophytic plants, saline soil, salt accumulator, salt excluder

\footnotetext{
Received 23.06.2017/ Revised 09.09.2018/ Accepted 23.12.2018/ Published 01.05.2019

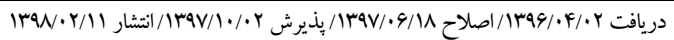


يكك كاتيون قابلتبادل در خاكك نواحى وسيعى از جهان اثرات

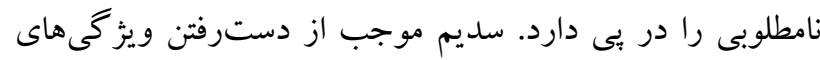

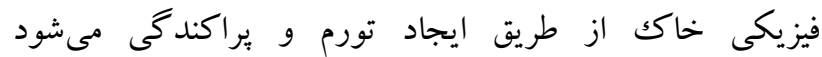
(Marschner, 2012). در خاككهاى داراى سديم مازاد، ذرات

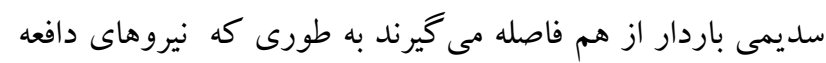

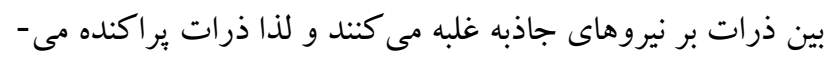

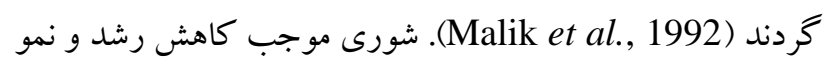

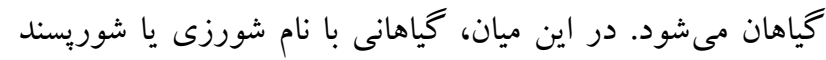

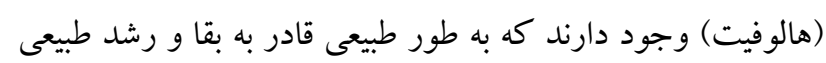

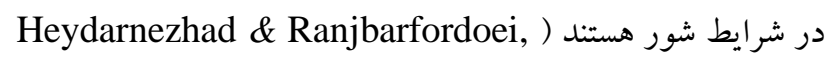

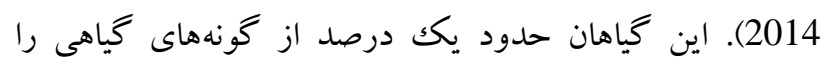

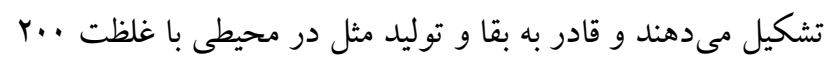
ميلىمولار NaCl (معادل حدود Taiz \& Zeiger, 2002; Manousaki \& Kalogerakis, ) 2011). عامل تعيين كننده در تحمل نمكك مازاد توسط گياهان

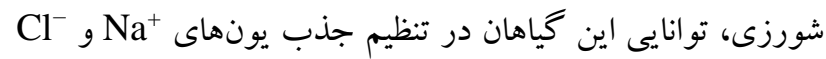
و در عين حال حفظ غلظتهاى سيتويلاسمى بتاسيم و منيزيم در حد مورد نياز براى فعالسازى فعاليتهاى آنزيمى ضرورى است

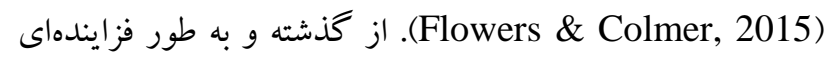

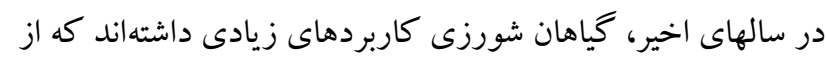
آن جمله كاربرد آنها در طب سنتى، شورىزدايى محيط، كياه يّالايى و استفاده به عنوان علوفه دام، غذاى انسان، دانههاى روغنى إنى

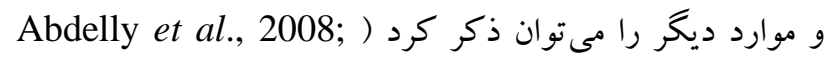
(Yensen, 2008; Liang et al., 2017 جهت به حداكثر رساندن بهرهورى محصول در نواحىاى كه

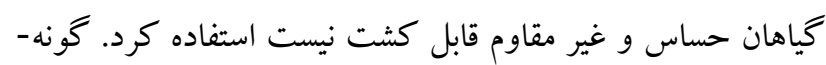

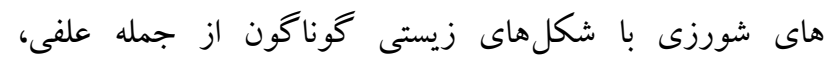

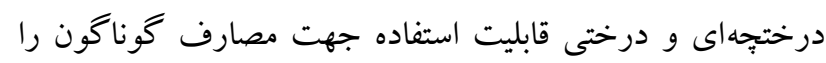

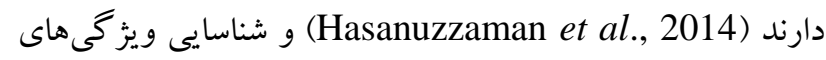
كونا كون آنها مى تواند كاربرد آنها را هدفمند سازد.

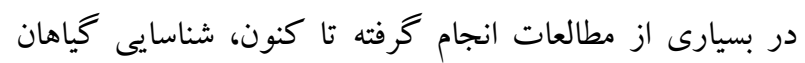
شورزى بيش از آنكه معطوف به بررسى عناصر و يونها در بافت إنس

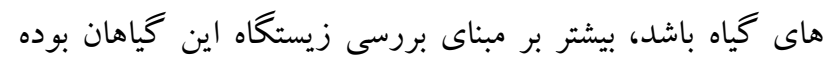

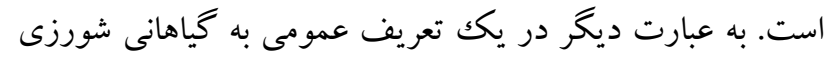
اطلاق مىشود كه قادر به تكميل جرخه حيات خود درد در زيستخاه dollo

يكى از مشكلات فراكير و محدود كننده توليد بايدار كشاورزى در ايران شورى خاك و آب است. بخشهاى وسيعى از مساحت

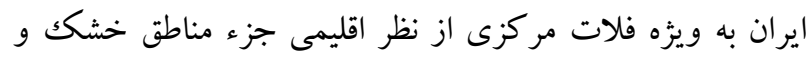

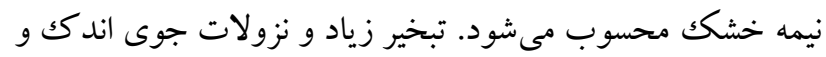
يراكنده در اين مناطق موجب تجمع نمككهاى مختلف در در لايه

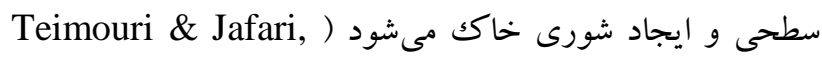

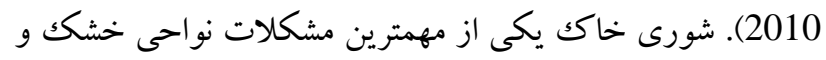

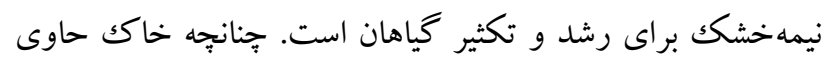

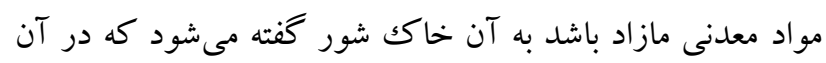
كياهان با تنش شورى مواجه مىشوند (Taiz \& Zeiger, 2002).

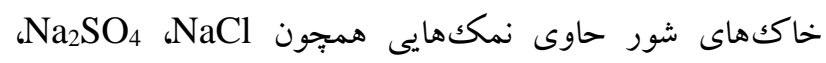

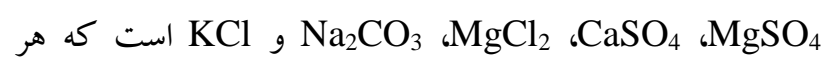
كدام در ايجاد تنش شورى نقش ايفا مى كنند اما كلريد سديم

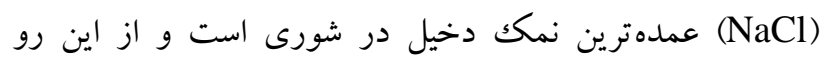

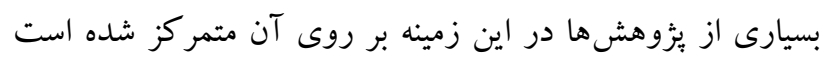
(Tavakkoli et al., 2010)

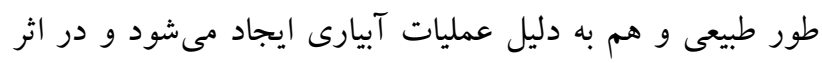

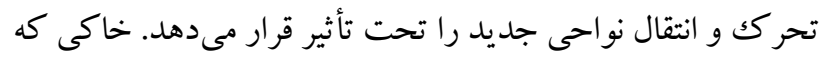

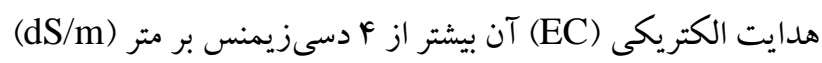

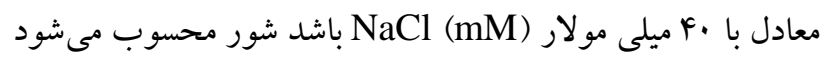

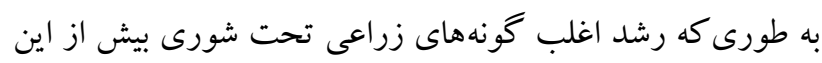

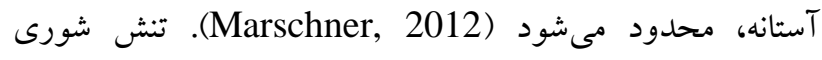
(نمكك) در گياهان به طور عمده ناشى از سميت يونى $\mathrm{Cl}^{-} \mathrm{Ca}^{-} \mathrm{Na}^{+}$

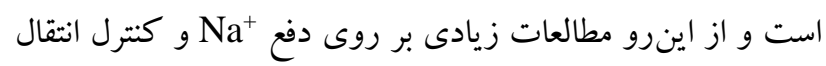
آن در گياه انجام شده است (Hasanuzzaman et al., 2014). به عنوان مثال بيشييانى ناقل سديمى NHX1 در آرابيدويسيس

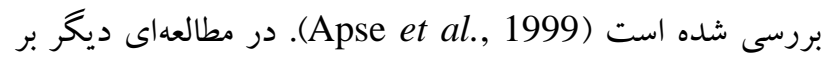
روى همين گياه با بررسى بيشيانى بمٍ واكوئلى بيروفسفاتاز

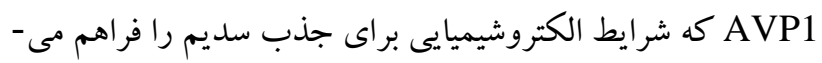
كند مشخص شد كه انباشت سديم و تحمل به شورى گياه

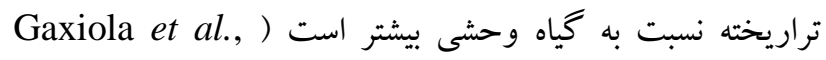

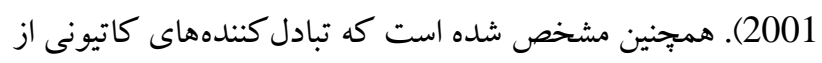

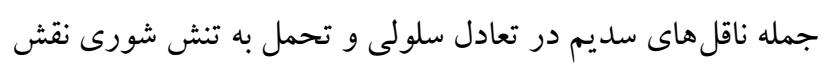

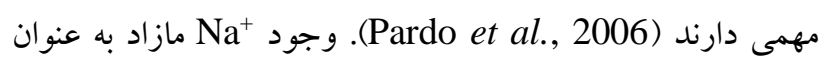


در مطالعه حاضر نمونههاى گياهى از منطقهاى كويرى در اطراف شهرستان خوسف واقع در استان خراسان جنوبى در شرق ايران

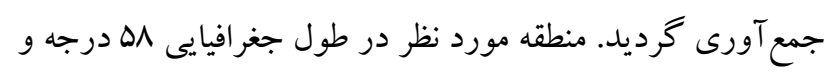

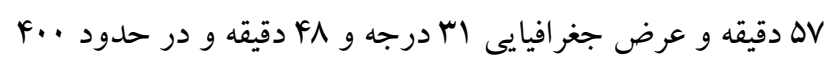
متر بالاتر از سطح دريا قرار دارد و در زمره كويرهاى مركزى ايران

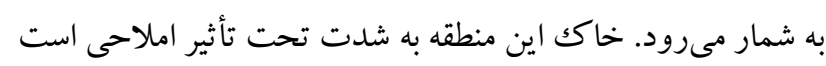
كه شورى خاكك را به حدى افزايش مىدهند كه تنها كياهان هالوفيت يا شورزى قادر به بقا در جنين شرايطى باشند. از آنجا كه مكان انتخاب شده براى جمع آورى نمونهاى گياهى تحت تأثير

آب شور نيز قرار دارد، لذا شورى خاكك تشديد هم شده است.

نمونهبردارى و بروسى خاكى منطقه مورد مطالعه

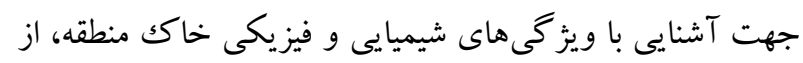
لايه سطحى خاكك تاعمق ·r سانتىمتر در سه نقطه مختلف منطقه در محدوده طول و عرض جغر افيايى ذكر شده در بخش قبل نمونه بردارى صورت گرفت. سبس نمونهها جهت حصول يكك نمونه واحد به نسبت يكسان با هم مخلوط شده و جهت آناليز خاكك به آزمايشگاه شيمى خاكك منتقل كرديد. بافت خاكى با روش هيدرومترى مورد سنجش قرار كرفت (Klute, 1986). يس از تهيه عصاره اشباع خاكك، هدايت الكتريكى (EC) و اسيديته (pH) خاكك به ترتيب توسط EC متر و pH متر سنجش كرديد. تعيين غلظت بى كربنات به روش تيتراسيون با اسيد سولفوريكك انجام

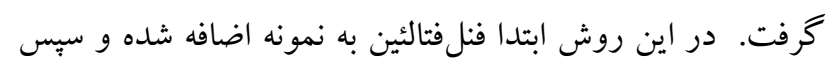
محلول حاصل تا زمان تغيير رنخك از صورتى به سفيد با اسيد سولفوريكك تيتر گرديد و در انتها با توجه به حجم اسيد مصرفى لهم

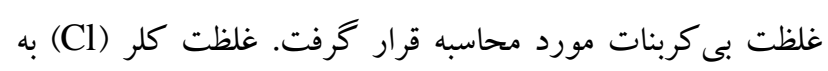
روش تيتراسيون با نيترات نقره تعيين گرديد.در اين روش به مقدار

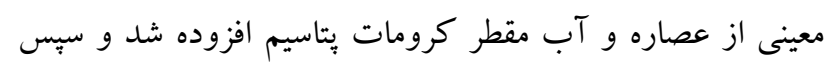
محلول حاصل تا تغيير رنگك از زرد روشن به نارنجى متمايل به قهوهاى با نيترات نقره تيتر گرديد. غلظت كاتيونهاى سديم (Na)

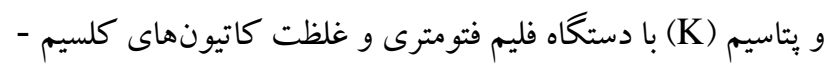
(Ca) و منيزيم (Mg) به روش كميلكسومترى مورد سنجش قرار

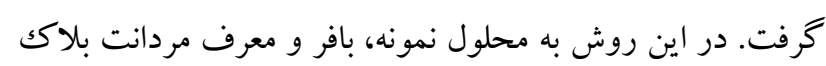

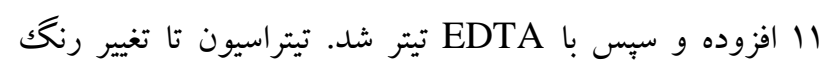

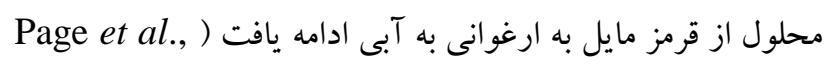

شور باشند. به عنوان مثال در مرور كلى و دستهبندى گونههاى

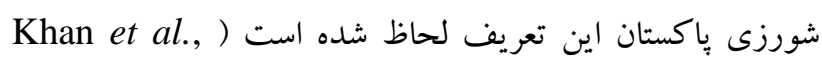
2003). با اين وجود مطالعاتى نيز وجود دارند كه به بررسى انباشت نمكك در بافت هاى مختلف كياهان شورزى و تشخيص مكانيسم تحمل آنها به شرايط شور تحت شرايط طبيعى برداختهاند. در

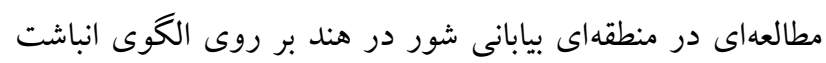
يونها در Sporobolus marginatus Hochst. ex A.Rich Aeluropus lagopoides L. كه اين كونها بيشتر سديم را در ريشهها انباشته مى كنند (Mangalassery et al., 2017) گياه ساحلى Arthrocnemum indicum (Willd.) Moq. منطقهاى كه مرتباً در معرض آب شور دريا قرار مى گيرد مشخص

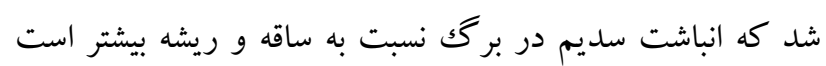

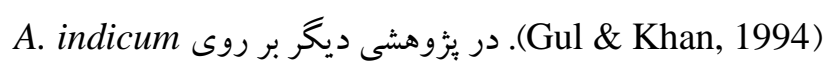
و .Suaeda fruticosa Forssk. ex J.F.Gmel در منطقهاى با خاكك شور، بررسى غلظت سديم در خاكك و بافتهاى كياه نشان داد كه اندامهوايى سهم قابل توجهى در شورىزدايى خاكى بـ ريزوسفر دارد (Rabhi et al., 2009). به دليل كمبود ييشرونده منابع آب و شورىشدن فزاينده خاكك به دليل تغييرات اقليمى و توسعه سريع كشاورزى مبتنى بر آبيارى، ارزيابى كونه هاى شورزى محلى از جهات گوناكون اهميت زيادى در استفاده كاربردى از آنها در نواحى خشك و نيمه خشك داري دارد ( Abdelly et (al., 2008; Liang et al., 2017 شورىزدايى منطقهاى معين باشد، جهت انتخاب كونههاى مناسب براى اين منظور تشخيص مكانيسم تحمل شورى (از جمله دفع يا انباشت نمكك) توسط آنها نقش تعيين كنندهاى دارد زيرا به عنوان نمونه، انتخاب يكك كونه دفع كنده نمكك با هدف ذكرشده كاملاً

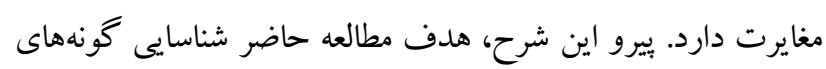

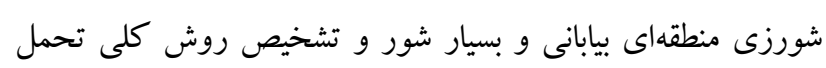
شورى (دفع يا انباشت نمكك) توسط اين كياهان با بررسى جذب سديم در ريشه و اندامهوايى و مقايسه آن با مقدار سديم خاكك است.

مواد و دوش ها توصيف منطقه جمع آورى نمونه هاى گياهى 
اى دانكن از نرم افزار Mstat-C استفاده شد. اختلاف معنىدار در سطح ه••

نتايج و بحث آناليز خاكى

نتايج آناليز خاكى (جدول r) نشان داد كه خاكك منطقه از نوع

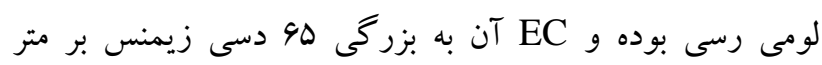

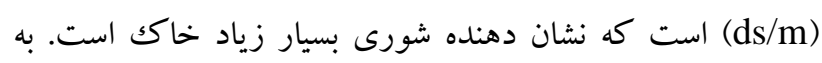

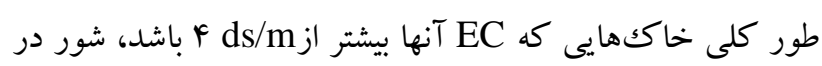
نظر گرفته مىشوند (Marschner, 2012). مطابق نتايج، شورى خاكك منطقه از شورى ميانگين آب درياها نيز بيشتر است. آب دريا

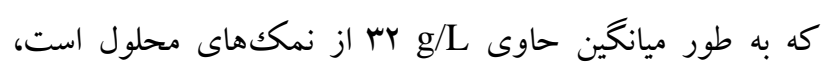
داراى EC معادل •ه است. (Taiz \& Zeiger, 2002). به عنوان

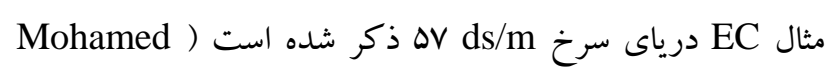
(Ahmed, 1997 . در مطالعه حاضر، سديم و كلر املاح عمده

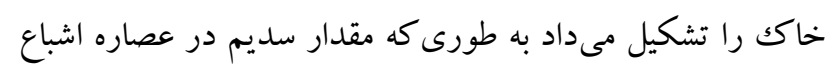

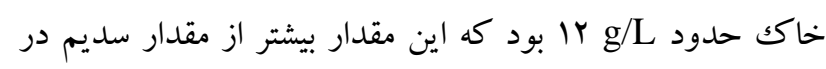

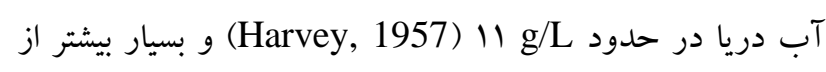
مقدار آن در محلول خاكك نواحى خشك و نيمه خشك (به طور

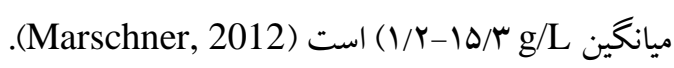
بر طبق محاسبات انجام شده مقادير SAR و ESP خاكك به

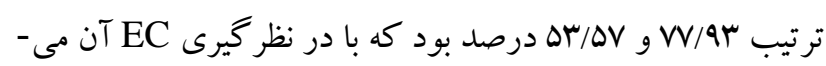
توان خاكك منطقه را در زمره خاككهاى شور-سديمى به شمار

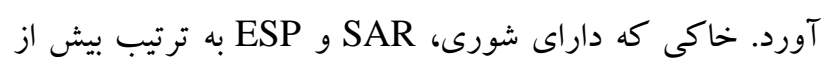
flds/m غلظت SAR .Sumner, 1993) غلظت كلسيم و منيزيم در محلول خاكك است. ساختار خاكى

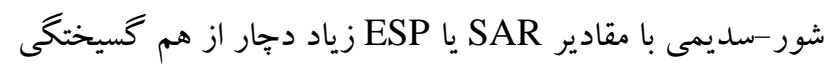

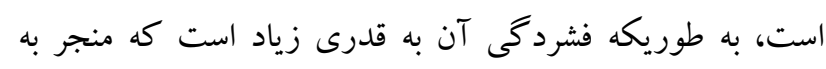

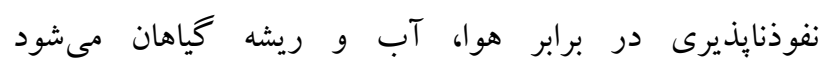
(Marschner, 2012) در ريشه و اندام هوايى گونههاى گياهى مورد بررسى، به طور معنى دارى نسبت به خاكك انباشته شده است. انباشت سديم در ريشه و اندام هوايى كياهان

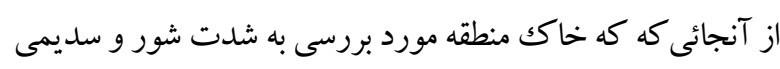

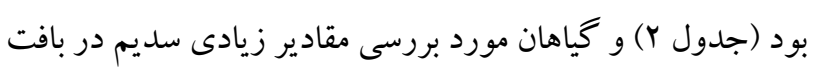

1994). نسبت جذب سديم (SAR) و درصد سديم تبادلى (ESP)

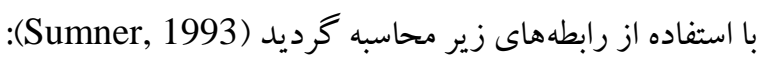
$\mathrm{SAR}=\mathrm{Na} /([\mathrm{Mg}+\mathrm{Ca}] / 2)^{0.5}(1)$ $\mathrm{ESP}=(1.475 \times \mathrm{SAR}) /(1+0.0147 \times \mathrm{SAR})(r)$ نمونهبردارى از كياهان و بروسى غلظت سديم

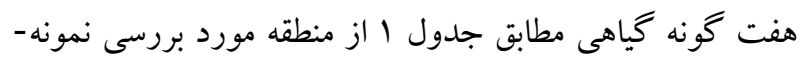

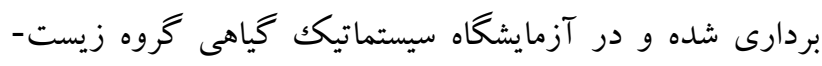
شناسى دانشگاه بيرجند به طور دقيق مورد شناسايى قرار كرفتند.

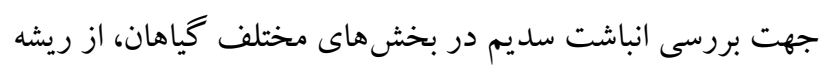

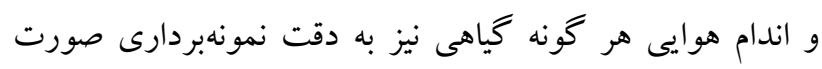

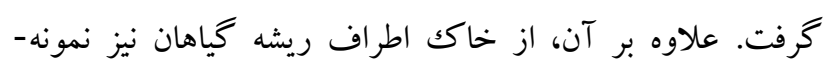

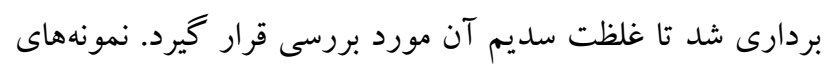

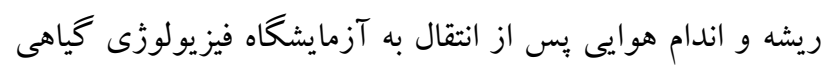

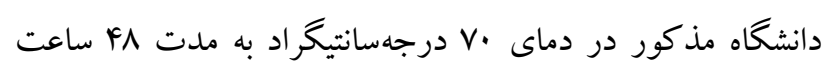

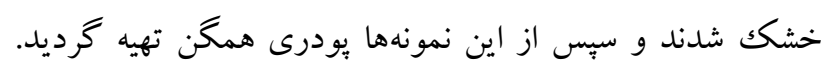
غلظت سديم در نمونههاى يودر شده گياهى و خاككهاى نمونه

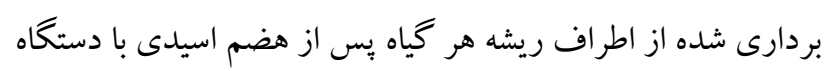

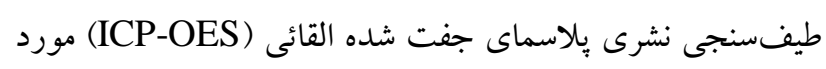
سنجش قرار گرفت (Uddin et al., 2016).

\section{محاسبه ضرايب انباشتكى سديم در اندامهاى مختلف رئل كياه}

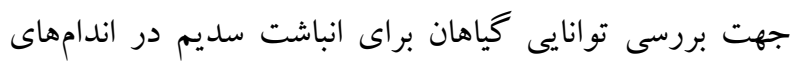

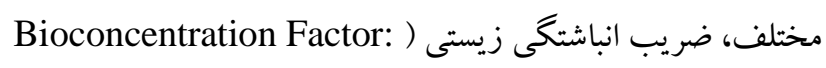
Translocation factors: در ريشه، ضريب تراجايى (BCF

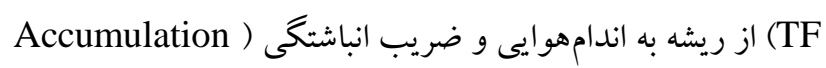

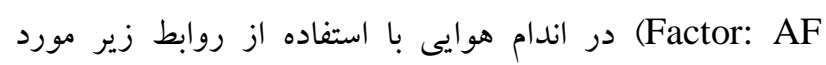
محاسبه قرار گرفت (Marrugo-Negrete et al., 2016)

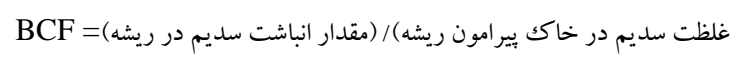

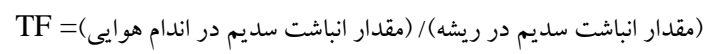

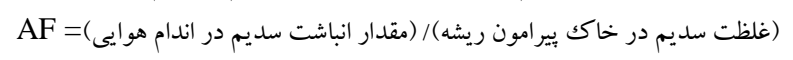
بروسى آمارى در مطالعه حاضر نمونهبردارى به صورت كاملاً تصادفى (طرح

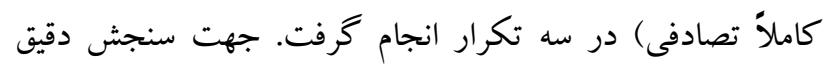

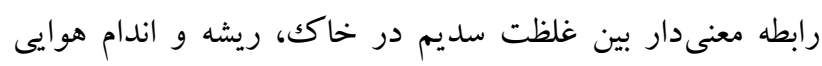

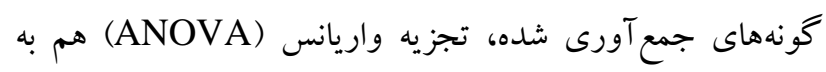

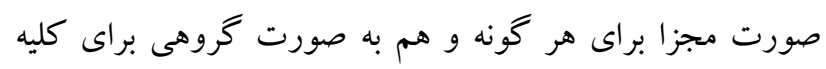

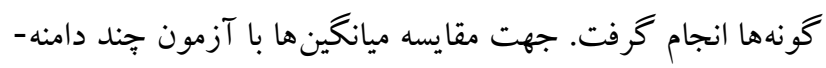




$$
\text { جدول ا- نام علمى، نام فارسى و تيره گونهاى گياهى مورد بررسى. }
$$

Table 1. Scientific and Persian names, and family of the studied species.

\begin{tabular}{|c|c|c|}
\hline نام تيره & 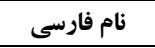 & نام علمى \\
\hline Zygophyllaceae & قيج & Zygophyllum eurypterum Boiss. \\
\hline Polygonaceae & ميرند كوهى & Pteropyrum olivieri Jaub. \& Spach \\
\hline Asteraceae & خرخه & Launaea arborescens (Batt.) Murb \\
\hline Amaranthaceae & يشموك & Aerva javanica (Burm. f.) Juss. ex Schult \\
\hline Asteraceae & درمنه سفيد & Artemisia santolina Schrenk \\
\hline Zygophyllaceae & 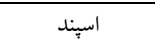 & Peganum harmala $\mathrm{L}$. \\
\hline Asteraceae & كك كش بيابانى & Pulicaria gnaphalodes (Vent.) Boiss \\
\hline
\end{tabular}

$$
\text { جدول r- برخى از ويز گیى هاى فيزيكى و شيميايى خاكك منطقه مورد مطالعه. }
$$

\begin{tabular}{|c|c|c|c|c|c|c|c|c|}
\hline \multicolumn{6}{|c|}{$\begin{array}{c}\text { غلظت كاتيونها و آنيونها } \\
\text { Concentration of cations and anions (ppm) }\end{array}$} & \multirow{2}{*}{$\begin{array}{c}\mathbf{E C} \\
(\mathbf{d s} / \mathbf{m})\end{array}$} & \multirow{2}{*}{$\mathbf{p H}$} & \multirow{2}{*}{ بافت خاكى } \\
\hline 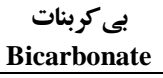 & $\begin{array}{c}\text { קتاسيم } \\
\text { Potassium } \\
\end{array}$ & 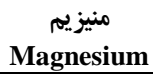 & كلسيم & $\begin{array}{c}\text { كلj } \\
\text { Chlorine } \\
\end{array}$ & سديم & & & \\
\hline$F \Delta \cdot N / \Delta)$ & $A V Y / 1 \Delta$ & $\Delta H_{N} / \mu^{G}$ & $\Lambda ৭ \Delta / \vee q$ & IFGNG/Yr & $11901 / 1 \mathrm{r}$ & 90 & $\Lambda / \Delta$ & 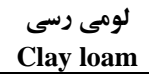 \\
\hline
\end{tabular}

Table 2. Some physical and chemical properties of the soil in the studied area.

- C. eurypterum .Chermahini et al., 2014 درختجهاى بيابانى است كه در آسياى مركزى، ايران و افغانستان مى رويد (Beier et al., 2003). با در نظر گيرى غلظت سديم در خاكك، علىرغم آنكه اين گونه بيشترين تجمع سديم را نسبت به ساير گونهها

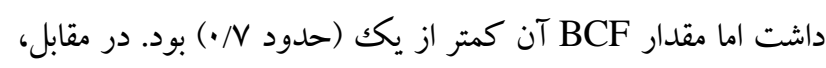
كونه L. arborescens بيشترين مقدار BCF (حدود I) را داشت. اين گونه كه از تيره Asteraceae است، گياهى درختجهاى خاردار با ارتفاع •ها-••ه سانتىمتر است كه بيشتر در مناطق نيمه بيابانى زيست دارد. بركَهاى اين گياه باريك است و ساقهاى زيخزاكى دارد (Schütz \& Milberg, 1997; Ghrabi, 2005)

$$
\text { ساير گياهان اندكك و به ترتيب نزولى زير بود (جدول ه): }
$$

A. javanica $>$ A. santolina $>$ Pt. olivieri $>P$. harmala $>$ Pu. gnaphalodes

دو گونه A. javanica و كه كمترين مقدار ACFtolina sant

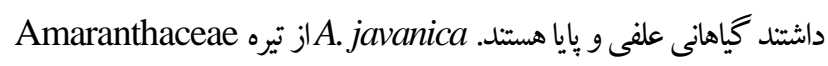
بومى آفريقاست (Samejo et al., 2012) و در نواحى خشك بر روى رسوبات شنى بر اكنش دارد. اين كياه جهت ممانعت از فرسايش خاكى بسار مناسب است (Phondani et al., 2015). كونه santolina) از تيره Asteraceae در سرتاسر شمالشرقى ايران به ويثه استانهاى خراسان در نواحى شنى يراكنده است (Mozaffarian, 1996).
ريشه و اندام هوايى انباشته كرده بودند (شكل ()، لذا گياهان مذكور كياهان شورزى (هالوفيت) هستند. با اين وجود، اين كونهها بيش از اين نيز در برخى منابع علمى به عنوان شورزى معرفى شدهاند Khan et al., 2003, 2006, 2015; Breckle et al., ) 2012). در حاليكه اغلب كياهان زراعى تحمل شورى خاكك بيش

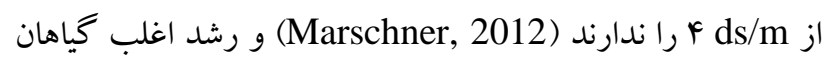
تحت شورى Kotuby-Amacher م-1 م ds/m محدود مى مود a) (et al., 2000 شرايط شورى بسيار زياد خاك (90ds/m) قادر به بقا بودند. نتايج تجزيه واريانس انباشت سديم در ريشه، اندامهوايى و خاكك ييرامونى گونه هاى گياهى هم به صورت مجزا براى هر كونه و هم به صورت گروهى با درنظر گيرى همه گونه ها به ترتيب در جداول rو F ارائه شده است. مقدار انباشت سديم در موارد مذكور نيز در شكل ا نشان داده شده است. با توجه به مقايسه ميانگين گروهى، در بين كياهان مورد بررسى، بيشترين انباشت سديم در ريشه و اندامهوايى كونه Z. eurypterum مشاهده شد كه اختلاف آن نسبت به ريشه و اندامهوايى ساير گونهها معنىدار بود (ه • P (P). گونهاى سرده Zygophyllum كه بزركترين سرده تيره Zygophyllaceae هmini- ( Amتند و قادر به بقا تحت شرايط سخت و بيابانى هستند 


$$
\text { جدول r - نتايج تجزيه واريانس انباشت سديم در نمونهاى خاكى، ريشه و اندامهو ايى هر گونه گياهى (آناليز مجزا براى هر گونه). }
$$

Table 3. ANOVA results of sodium accumulation in samples of soil, root, and aerial parts of each species (separate analysis for each species).

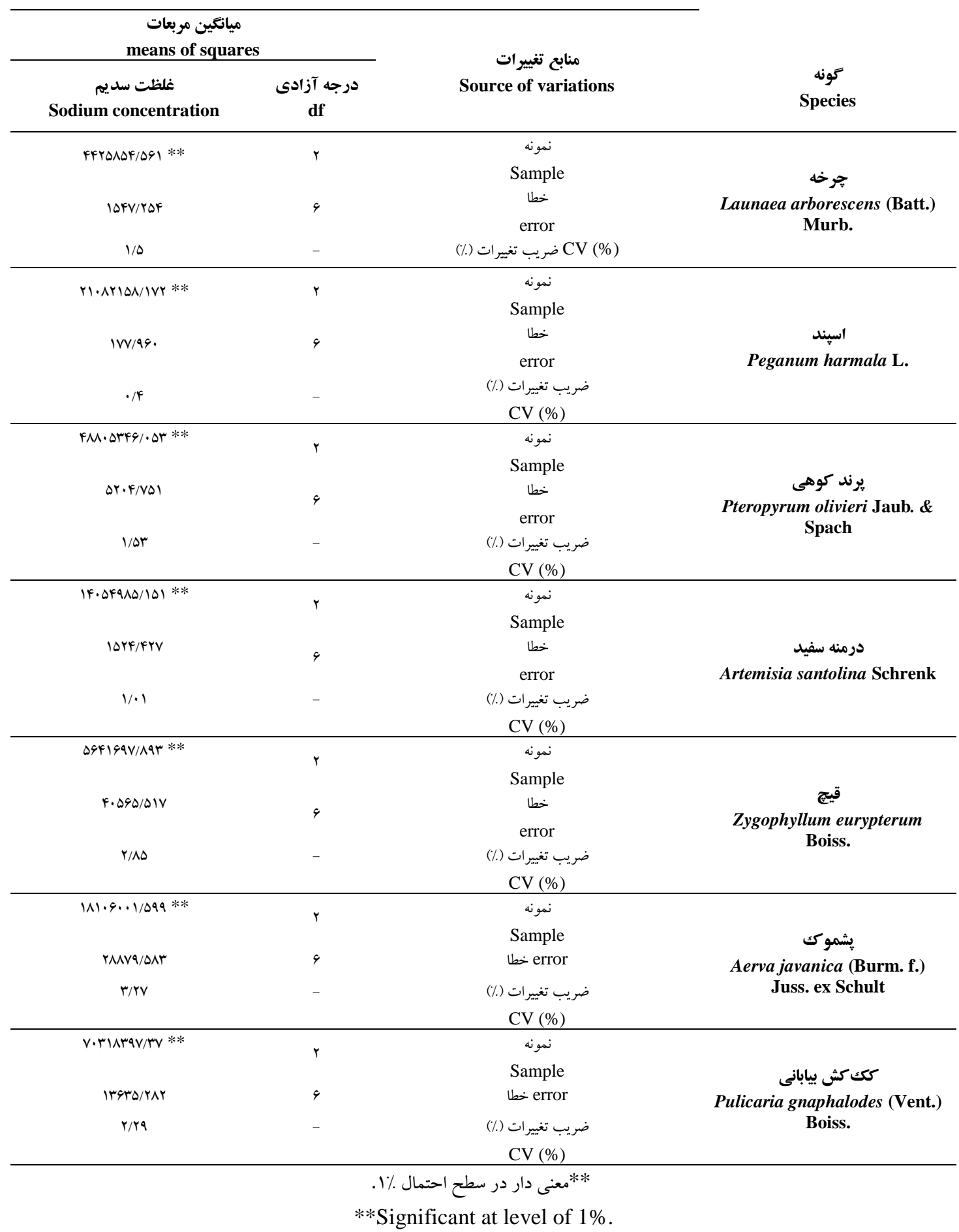

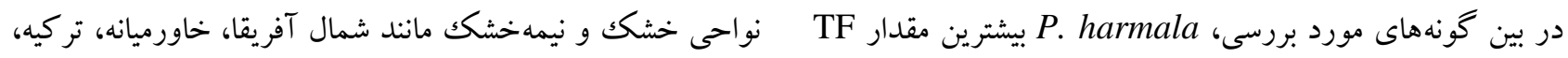

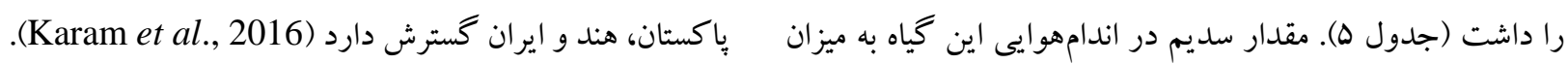

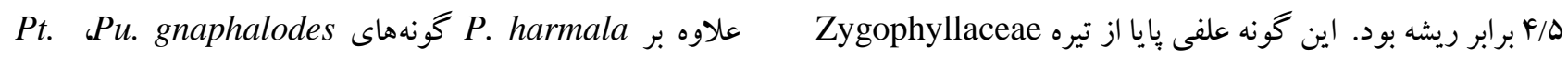

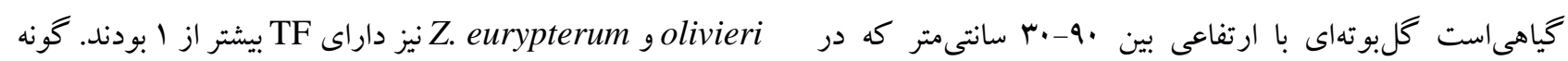




$$
\text { جدول f- - نتايج تجزيه واريانس انباشت سديم درنمونهاى خاكى، ريشه و اندامهوايى گونهاى گياهى (آناليز گروهى). }
$$

Table 4. ANOVA results of sodium accumulation in samples of soil, root, and aerial parts of species (overall analysis).

\begin{tabular}{|c|c|c|}
\hline \multicolumn{2}{|c|}{$\begin{array}{c}\text { ميانكين مربعات } \\
\text { means of squares }\end{array}$} & \multirow{2}{*}{$\begin{array}{c}\text { منابع تغييرات } \\
\text { Source of variations }\end{array}$} \\
\hline $\begin{array}{c}\text { غلظت سديم } \\
\text { Sodium concentration }\end{array}$ & $\begin{array}{c}\text { درجه آزادى } \\
\text { df }\end{array}$ & \\
\hline 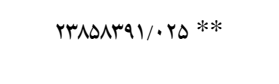 & r. & $\begin{array}{c}\text { نمونه } \\
\text { Sample }\end{array}$ \\
\hline $\mid r \cdot v q / r q 9$ & Fr & $\begin{array}{c}\text { خ } \\
\text { error }\end{array}$ \\
\hline$r / \Delta$ & - & $\begin{array}{l}\text { ضريب تغييرات (\%) } \\
\text { CV (\%) }\end{array}$ \\
\hline
\end{tabular}

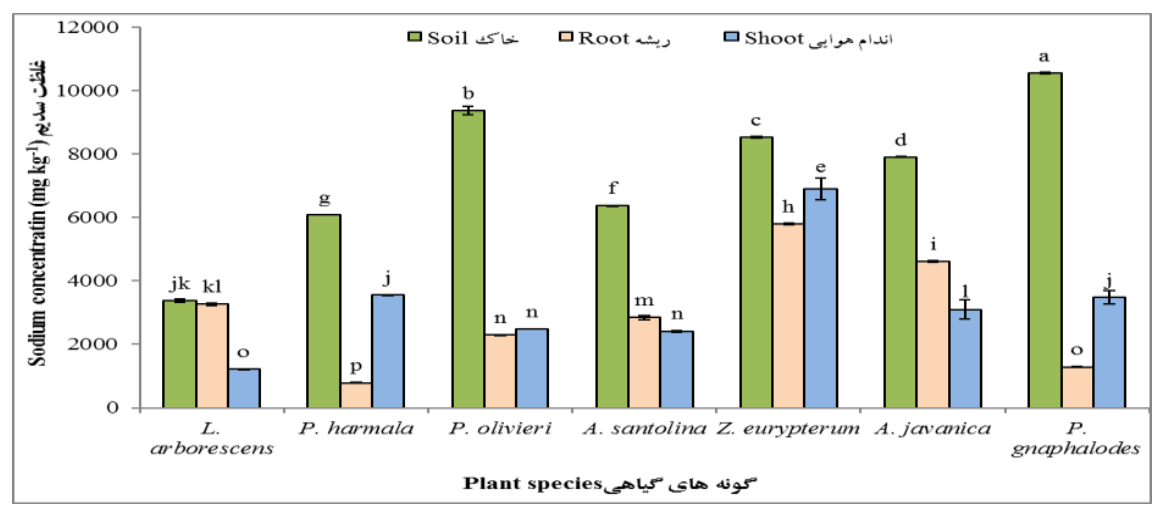

شكل ا - غلظت سديم در ريشه و اندام هوايى گياهان و خاك اطراف آنها. حروف متفاوت نشان دهنده معنىدارى در سطح ه./P> است.

Fig. 1. Sodium concentration in roots and shoots of plants and their rhizosphere soil. Different letters indicate significant differences at $\mathrm{P}<0.05$.

Nouri et al., 2011; Marrugo-Negrete et al., ) هستند

مقدار AF نشاندهنده قابليت ويزه يك كياه براى جذب يونهاى فلزى از خاكك و انتقال آن به بخشهاى هوايى است ( Vikram Ghavri et al., 2013 مورد ارزيابى در بثوهش حاضر جهت انباشت سديم در بخشهاى هوايى قابل برداشت مناسب نبود به طورى كه هيج يك مقدار AF

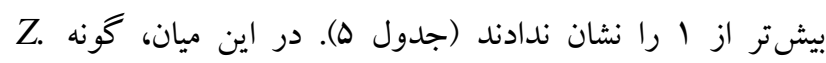

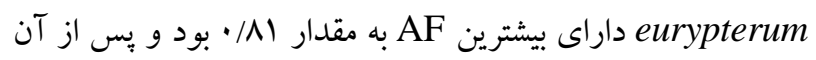
AF به P. harmala كونهاى ارزيابى شده كمتر از ه/ • و به صورت روند نزولى زير بود: A. javanica $>$ A. santolina $>$ L. arborescens $>P u$. gnaphalodes $>$ Pt. olivieri

راه كارهاى مختلفى براى تحمل شورى توسط گياهان وجود دارد كه عمدهترين آنها شامل دفع يا جذب املاح است. دفع كندهها، نمكك را

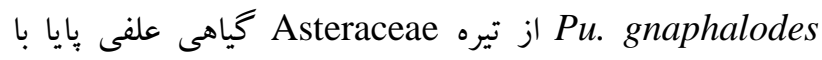
ساقهاى افراشته و گل هاى زرد رنگك است كه حدود .ب-.1

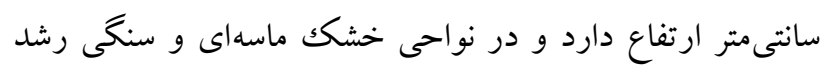
مى كند. اين كياه در ايران، مصر، ياكستان، هند، تركيه و عربستان توزيع يافته است (

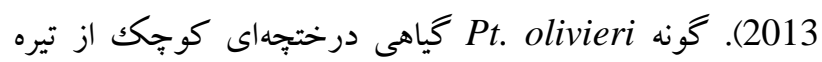
Polygonacea است. اين كياه در خاككهاى كم عمق حاوى ماسه درشت و شن يافت مىشود ( Piri sahragard et al., 2016; Naseem et

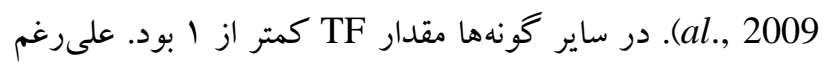
اينكه گونه L. arborescens داراى بيشترين مقدار BCF بود اما اين كياه مقدار TF قابل توجهى را نشان نداد كه نشاندهنده انتقال اندكك سديم از ريشه به اندامهوايى آن است. براى يكك فلز يا آلاينده مشخص، كياهانى كه مقادير BCF و TF آنها بيش از يك آ باشد جهت استخراج و حذف آن از محيط آلوده بسيار مناسب 
جدول ه- ضريب انباشتكى زيستى (BCF) سديم در ريشه، ضريب تراجايى (TF) سديم از ريشه به اندامهو ايى و ضريب انباشتخى (AF) (BCF) آن در اندام هو ايى.

Table 5. Bioaccumulation factor (BCF) of sodium in roots, translocation factor (TF) of sodium from roots to shoots, and its accumulation factor (AF) in aerial parts.

\begin{tabular}{|c|c|c|c|}
\hline $\mathbf{A F}$ & TF & BCF & \\
\hline .149 & 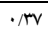 &.$/ a v$ & ) جرخه (L. arborescens) \\
\hline$\cdot / \Delta \Lambda$ & $F / \Delta 1$ &.$/ \pi$ & اسبند (P. harmala) \\
\hline$\cdot / 49$ & $1 / \cdot 1$ & $\cdot / r F$ & يرند كوهى (Pt. olivieri) \\
\hline ה ז & $\cdot / \wedge \Delta$ & $.1 \% \Delta$ & درمنه سفيد (A. santolina) \\
\hline$\cdot / \mathrm{N}$ & 1/199 & .191 & قيج (Z. eurypterum) \\
\hline$\cdot \pi q$ & $.19 \mathrm{~V}$ & $\cdot / \Delta \mathrm{A}$ & بشموك (A. javanica) \\
\hline . & $r / N$ & . $/$ r & ككك كث بيابانى (Pu. gnaphalodes) \\
\hline
\end{tabular}

به طور غالب از سديم و يتاسيم تشكيل شده است ( Waisel, 1972). گياه ساليكورنيا نيز به شدت متحمل به نمكك بوده و قادر است تا •F-r.r درصد وزن خشك خود سديم كلريد را انباشته

نمايد (Sharma, 2010).

\section{نتيجحه تيرى}

بررسى انباشت سديم در هفت كونه شورزى بومى نواحى بيابانى و بسيار شور ايران به منظور شناسايى راهكار تحمل شورى نشان داد كه همه كونه هاى مورد بررسى دفع كننده سديم هستند. اين نتيجه با توجه به اين يافته كه مقادير BCF و AF سديم براى تمامى كونه ها كمتر از يكك بود به دست آمد. اين يافته نشاندهنده انباشت كمتر

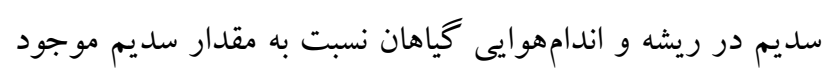

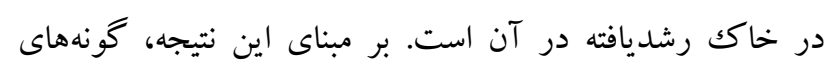

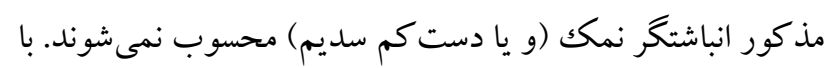
اين وجود مى توان از اين كياهان جهت تثبيت نمك و وبيشخيرى از از انتشار املاح در هوا و آبهاى زيرزمينى استفاده كرد. از سوى ديخر از آنجائيكه كه اين كياهان زيتوده قابل توجهى دارند و مقدار انباشت سديم در اندامهاى آنها نسبت به خاكك معنىدار است

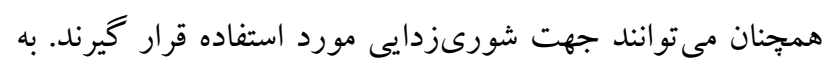
عبارت ديخر، ممكن است اسفاده از گياهى بازيتوده زياد و انباشت كمتر نسبت به گياه انباشتكرى كه زيتوده اندكى دارد جهت شورىزدايى صرفه اقتصادى بيشترى داشته باشد.

\section{سياسگز ارى}

نويسند گان از حمايتهاى معاونت بزوهشى دانشگاه بيرجند در

$$
\text { انجام اين بزظوهش قدردانى مىنمايند. }
$$

در سطح ريشه يا ريزوسفر دفع مى كنند و بنابراين در زيتوده خود مقدار نمكك اندكى دارند. در مقابل، جذب كنندهها يا انباشتخرها املاح را در سلولها يا غدههاى ويثهاى در داخل يا روى سطح تنه كياه ذخيره مى كنند (Abdelly et al., 2008). در مطالعه حاضر، نظر به اين كه سديم انباشته شده در بافتهاى كونه هاى مورد بررسى كمتر از مقدار سديم موجود در خاكك رشديافته در آن بود (كه اين يافته در مقادير BCF و AF كمتر از يكك براى تمام كونهها نهفته

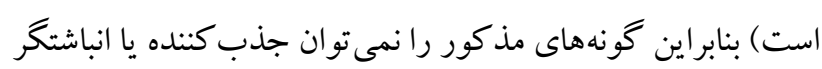
نمكك (و يا دست كم سديم) در نظر گرفت. در مقابل، نتايج نشان مى دهد كه اين كونهها دفع كننده نمكك و يا حداقل دفع كننده سديم هستند. دفع سديم به طور عمده به واسطه جذب خالص اندكك آن توسط سلولهاى ريشه و كنترل شديد بار گيرى خالص آوند جوبى به توسط سلولهاى يارانشيمى در استوانه آوندى صورت مى گئه

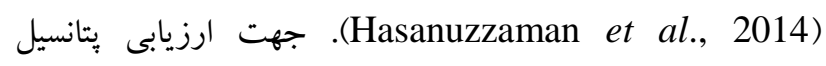
استخراج يكك فلز (مانند سديم) به وسيله يكك گونه گياهى مشخص، فاكتورهاى BCF و AF اهميت بيشترى نسبت به غلظت تام آلاينده در بخـش هـوايى و ريشه دارد. اين فاكتورها در كونه -

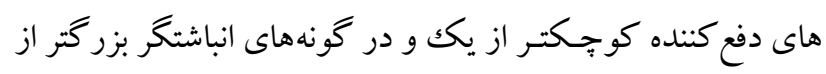
يكك است (Babaakbari et al., 2013). در حالى كه در مطالعه حاضر مقدار سديم در بافتهاى گونههاى مورد بررسى كمتر از يكك درصد وزن خشكك گياه را تشكيل مىدهد اما در گونههاى انباشتخر اين مقدار كاه به ·r درصد و بيش از آن مىرسد. به عنوان Suaeda monoica نمونه گزارش شده است كه در برگكهاى Forssk. ex J.F.Gmel. تشكيل مىدهد. همجنين گزارش ديخرى وجود دارد كه محتواى

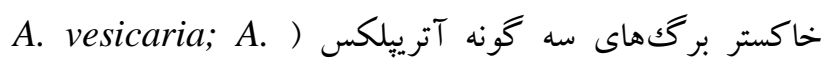

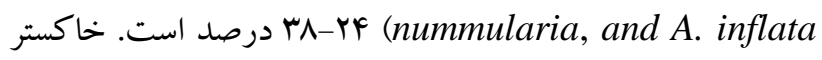




\section{REFERENCES}

Abdelly, C., Öztürk, M., Ashraf, M. and Grignon, C. 2008. Biosaline agriculture and high salinity tolerance: - Springer Science \& Business Media, Berlin \& Heidelberg. 370 pp.

Amini-Chermahini, F., Ebrahimi, M., Farajpour, M. and Taj Bordbar, Z. 2014. Karyotype analysis and new chromosome number reports in Zygophyllum species. - Caryologia 67: 321-324.

Apse, M.P., Aharon, G.S., Snedden, W.A. and Blumwald, E. 1999. Salt tolerance conferred by overexpression of a vacuolar $\mathrm{Na}+/ \mathrm{H}+$ antiport in Arabidopsis. - Science 285: $1256-58$

Babaakbari, M., Farahbakhsh, M., Savaghebi, G.R. and Najafi, N. 2013. Investigation of arsenic concentration in some of the calcareous soils of Ghorveh and arsenic uptake by maize, wheat and rapeseed in a natural contaminated soil. - Water Soil Sci. 23: 1-17.

Beier, B.A., Chase, M. and Thulin, M. 2003. Phylogenetic relationships and taxonomy of subfamily Zygophylloideae (Zygophyllaceae) based on molecular and morphological data. - Plant Syst. Evolut. 240: 11-39.

Breckle, S.W., Wucherer, W., Dimeyeva, L.A. and Ogar, N.P. 2012. Aralkum-a Man-Made Desert: The Desiccated Floor of the Aral Sea (Central Asia). Springer, Berlin \& Heidelberg. 488 pp.

Flowers, T.J. and Colmer, T.D. 2015. Plant salt tolerance: adaptations in halophytes. - Annal. Bot. 115: 327-331.

Gaxiola, R.A., Li, J.S., Undurraga, S., Dang, L.M., Allen, G.J., Alper, S.L. and Fink, G.R. 2001. Drought- and salttolerant plants result from overexpression of the AVP1 $\mathrm{H}^{+}$-pump. - Proc. Natl. Acad. Sci. USA. 98:11444-11449.

Ghavri, S.V., Bauddh, K., Kumar, S. and Singh, R.P. 2013. Bioaccumulation and translocation potential of $\mathrm{Na}+$ and $\mathrm{K}+$ in native weeds grown on industrially contaminated soil. - Int. J. Chem. Tech. Res. 5: 18691875.

Ghrabi, Z. 2005. A guide to medicinal plants in North Africa. - IUCN Centre for Mediterranean Cooperation, Malaga. 256 pp.

Gul, B. and Khan, M.A. 1994. Growth, osmoregulation and ion accumulation in the coastal halophyte Arthrocnemum indicum under field conditions. - Pak. J. Marine Sci. 3:115-123.

Harvey H.W. 1957. The chemistry and fertility of sea waters. - J. Chem. Educ. 34: p 51.

Hasanuzzaman, M., Nahar, K., Alam, M., Bhowmik, P. C., Hossain, M., Rahman, M. M., Prasad, M.N.V., Ozturk, M. and Fujita, M. 2014. Potential use of halophytes to remediate saline soils. - BioMed. Res. Int. 2014: 1-12.

Heydarnezhad, S. and Ranjbarfordoei, A. 2014. Effects of salt stress on growth characteristics and ion accumulation in saltwort plants (Seidlitzia rosmarinus L.). - Desert Ecosyst. Engin. J. 3: 1-10.

Kamkar, A., Ardekani, M.R.S., Shariatifar, N., Misagi, A., Nejad, A.S. M. and Jamshidi, A.H. 2013. Antioxidative effect of Iranian Pulicaria gnaphalodes L. extracts in soybean oil. - South Afric. J. Bot. 85: 39-43.

Karam, M.A., Abd-Elgawad, M.E. and Ali, R.M. 2016.
Differential gene expression of salt-stressed Peganum harmala L. - J. Genet. Eng. Biotechnol. 14: 319-326.

Khan, M.A. 2003. An ecological overview of halophytes from Pakistan. -In: Lieth, H. (ed.), Cash crop halophytes: Recent studies. 167-187. - Springer, Dordrecht.

Khan, M.A., Böer, B., Kust, G.S. and Barth H.J. 2006. Sabkha Ecosystems: Volume II: West and Central Asia. - Springer, Netherlands, 263 pp.

Khan, M.A., Ozturk, M., Gul B. and Ahmed, M.Z. 2015. Halophytes for food security in dry lands. Academic Press, Elsevier Inc., 360 pp.

Klute, A. 1986. Methods of soil analysis. Part 1. Physical and mineralogical methods. - American Society of Agronomy inc., USA, 1188 pp.

Kotuby-Amacher, J., Koenig, R. and Kitchen, B. 2000. Salinity and plant tolerance. - Electronic Publication AG-SO-03, Utah State University Extension, Logan. $8 \mathrm{pp}$.

Liang, L., Liu, W., Sun, Y., Huo, X., Li, S. and Zhou, Q. 2017. Phytoremediation of heavy metal contaminated saline soils using halophytes: current progress and future perspectives. - Environ. Rev. 25: 269-281

Malik, M., Mustafa, M.A., and Letey, J. 1992. Effect of mixed $\mathrm{Na} / \mathrm{Ca}$ solutions on swelling, dispersion and transient water flow in unsaturated montmorillonitic soils. - Geoderma. 52: 17-28.

Mangalassery, S., Dayal, D., Kumar, A., Bhatt, K., Nakar, R., Kumar, A., Singh, J.P. and Misra, A.K. 2017. Pattern of salt accumulation and its impact on salinity tolerance in two halophyte grasses in extreme saline desert in India. - Ind. J. Exp. Biol. 55: 542-548

Manousaki, E. and Kalogerakis, N. 2011. Halophytes present new opportunities in phytoremediation of heavy metals and saline soils. - Ind. Eng. Chem. Res. 50: 656-660.

Marrugo-Negrete, J., Marrugo-Madrid, S., PinedoHernández, J., Durango-Hernández, J. and Díez, S. 2016. Screening of native plant species for phytoremediation potential at a $\mathrm{Hg}$-contaminated mining site. - Sci. total environ. 542: 809-816.

Marschner, P. 2012. Marschner's Mineral Nutrition of Higher Plants. 3rd Edition. - Academic Press, USA, pp 651 .

Mohamed Ahmed, M.S. 1997. Impact of diluted Red Sea water, irrigation frequency and organic mulch on Millet and Sorghum growth in a sandy soil. University of Kordofan, Sudan, $71 \mathrm{pp}$.

Mozaffarian, V. 1996. A dictionary of Iranian plant names. - Farhang Mo'aser, Iran, 671 pp.

Naseem, S., Bashir, E., Shireen, K. and Shafiq, S. 2009. Soil-plant relationship of Pteropyrum olivieri, a serpentine flora of Wadh, Balochistan, Pakistan and its use in mineral prospecting. - Studia UBB Geologia. 54: 33-39.

Nouri, J., Lorestani, B., Yousefi, N., Khorasani, N., Hasani, A., Seif, F. and Cheraghi, M. 2011. Phytoremediation potential of native plants grown in the vicinity of Ahangaran lead-zinc mine (Hamedan, Iran). - Environ. Earth Sci. 62: 639-644.

Page, A.L., Miller, R.H. and Keeney, D.R. 1994. Methods 
of soil analysis. Part 2. Chemical and microbiological properties. - Soil Science Society of America, Inc., Madison, Wisconsin, USA. 1159 pp.

Pardo, J.M., Cubero, B., Leidi, E.O. and Quintero. F.J. 2006. Alkali cation exchangers: roles in cellular homeostasis and stress tolerance. - J. Exp. Bot. 57: 1181-99.

Phondani, P.C., Bhatt, A., Elsarrag, E. and Alhorr, Y.M. 2015. Seed germination and growth performance of Aerva javanica (Burm. f.) Juss ex Schult. - J. Appl. Res. Medic. Aromat. Plants. 2: 195-199.

Piri sahragard, H., Zare Chahuoki, M. A. and Azarnivand, H. 2016. Developing predictive distribution map of plant species habitats using logistic regression (Case study: Khalajestan rangelands of Qum province). - J. Rangel. 9: 222234.

Rabhi, M., Hafsi, C., Lakhdar, A., Hajji, S., Barhoumi, Z., Hamrouni, M.H., Abdelly, C. and Smaoui, A. 2009. Evaluation of the capacity of three halophytes to desalinize their rhizosphere as grown on saline soils under nonleaching conditions. - Afric. J. Ecol. 47: 463-468.

Samejo, M.Q., Memon, S., Bhanger, M.I. and Khan, K.M. 2012. Chemical compositions of the essential oil of Aerva javanica leaves and stems. - Pak. J. Anal. Environ. Chem. 13: 5.

Schütz, W. and Milberg, P. 1997. Seed germination in Launaea arborescens: a continuously flowering semidesert shrub. - J. Arid Environ. 36: 113-122.

Sharma, A., Gontia, I., Agarwal, P.K. and Jha, B. 2010.
Accumulation of heavy metals and its biochemical responses in Salicornia brachiata, an extreme halophyte. - Marine Biol. Res. 6: 511-518.

Sumner, M.E. 1993. Sodic soils-New perspectives. - Soil Res. 31: 683-750.

Taiz, L. and Zeiger, E. 2002. Plant Physiology. - Sinauer Associates, Sunderland. $623 \mathrm{pp}$.

Tavakkoli, E., Rengasamy, P. and McDonald, G.K. 2010. High concentrations of $\mathrm{Na}^{+}$and $\mathrm{Cl}^{-}$ions in soil solution have simultaneous detrimental effects on growth of faba bean under salinity stress. - J. Exp. Bot. 61: 4449-4459.

Teimouri, A. and Jafari, M. 2010. The effects of salinity stress on some of anatomical and morphological characteristics in three Salsola species: $S$. rigida, $S$. dendroides, S. richteri. - Iran. J. Range Desert Res. 17: 21-34.

Uddin, A.H., Khalid, R.S., Alaama, M., Abdualkader, A.M., Kasmuri, A. and Abbas, S. 2016. Comparative study of three digestion methods for elemental analysis in traditional medicine products using atomic absorption spectrometry. - J. Anal. Sci. Technol. 7: 1-7.

Waisel, Y. 1972. Biology of halophytes. 395pp: Academic Press, New York and London.

Yensen, N.P. 2008. Halophyte uses for the twenty-first century. - In: Khan M.A. and Weber D.J. (eds.). Ecophysiology of high salinity tolerant plants. 367396. - Springer, Dordrecht.

How to cite this article:

Mousavi Kouhi, S.M., Moudi, M. Soltani Moghadam, E. and Sarchahi Moghadam, H. 2019. The investigating of sodium accumulation in some halophytic species of Zygophyllaceae, Polygonaceae, Asteraceae and Amaranthaceae. Nova Biol. Reperta 6: 96-105.

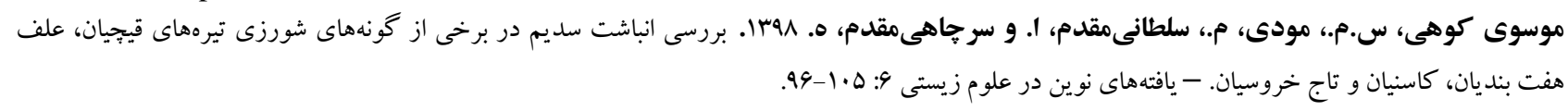

